\title{
The problem of educating multilingual person in Kazakhstani university
}

\author{
Zinaida Kekeeva ${ }^{1, *}$, Zamira Dorzhinova ${ }^{1}$, Gulshat Abugalieva ${ }^{2}$ \\ ${ }^{1}$ Kalmyk State University named after B. B. Gorodovikov, 11, Pushkina Street, Elista, 358000, Russia \\ ${ }^{2}$ West Kazakhstan State University named after M. Utemisov, 162, Dostyk-Druzhby Avenue, Uralsk, \\ 090000, Kazakhstan
}

\begin{abstract}
The topic of this paper considers multilingualism to have many social, psychological and lifestyle advantages for younger generation. Problem Statement. The article analyses the emphasis on multilingual education in Kazakhstan universities. Educators in Kazakhstan know the value of being multilingual and promote learning several languages because it will have positive cultural impacts on students. Purpose of the Study. This study is aimed at investigating a set of problems of forming a multilingual person in educational system in Kazakhstan and conducting an experiment for educating multilingual teachers who know foreign languages and traditions of their nation. Research Methods. The authors used theoretical, methodological, informational and analytical methods to justify the results of experiments of forming a multilingual person in Kazakhstan universities. Theoretical method is used to analyze theoretical and pedagogical literature concerning this problem. Experimental method and method of mathematical processing of research results were also used. Findings. Our experimental investigation has shown that future teachers follow national traditions by enriching themselves through ethno cultural spiritual and moral sources. Conclusion. The results of the research conducted in Western Kazakhstan state University named after Utemisov $M$. indicated that the process of learning national Kazakh traditions by future teachers encourages the formation of multilingual competence. The field of application the results. The article can be used in the development of lectures on theory and methodology of professional education, pedagogy of institutions of higher education, methodology of teaching native language, as well as in pedagogical work of teacher of philology at school.
\end{abstract}

\section{Introduction}

The aim of this study is to shed more lights on the process of formation the spiritual and moral component of a young person. The authors think that it greatly depends on the study of folk art, its traditions and modern development trends. Modern pedagogical education which is one of the priorities in Kazakh higher educational system should provide future teachers with multilingual competence. It will help them to be independent and creative in solving professional tasks in the specified context, in realizing the personal and social

\footnotetext{
* Corresponding author: kekeeva-zo@yandex.ru
} 
significance of the tasks facing the state and being responsible for the results of pedagogical activities.

Researchers G.S. Zhusupova and K.B. Amanzholova argue that nowadays some research needs to be conducted because the role of Kazakh national traditions in the formation of multilingual competence of teachers has not been investigated yet. There is a lack of theoretical grounds for developing the process of formation multilingual competence of future teachers on the basis of Kazakh national traditions in universities [1,2]

Modern Kazakh society is multilingual. It makes an attempt to find universal mechanisms of promoting successful language interactions of people. Scientists U. Ritzau, L.M.Madsen write that a language involves fluidity and fixity as a key feature of recognizable register in multilingual world. [3]

C. Perregaux, J. Sugarman argue that it is impossible for a population of modern state to speak only one language. Modern society faces different threats and challenges that is why people need to overcome language barriers and speak other languages as a means of communication [4]. M.O.Olnova believes that one of the main tasks of a modern family is to grow a multilingual citizen [5]. The educational system of Kazakhstan is developing an educational project "Trinity of Languages". It aims to develop three languages. The Kazakh language has the status of a state language, the Russian language is the language for communication between different nations within Kazakhstan, the English language is a language for communication with people from abroad. Scientists have developed stages for gradual shift of the Kazakh language to Latin script.

The main mechanism of practical realization of the project 'Trinity of Languages' in the educational system of Kazakhstan is the principle of 'double enter of knowledge': language education through learning language subjects and teaching individual mathematical and science subjects in a foreign language but teaching socio humanitarian subjects in Kazakh or Russian.

Practical realization of the project 'Trinity of Languages' in the educational system of Kazakhstan involves the following stages: 1)teaching of language subjects (Kazakh, Russian, English) with the introduction of optional lessons for improving the level language competence, 2) the teaching of subjects in three languages, 3) extracurricular activity (publishing the newspaper INSIDER, the work of TV station, drama club, the defense of scientific and research projects, expeditions, excursions).

These modern conditions of education require the formation of multilingual competence of future teachers who are able to be independent and creative in solving professional tasks in the specified context, in realizing the personal and social significance of the tasks facing the state and being responsible for the results of pedagogical activities. The main problem of Kazakh higher educational system is teaching a specialist with a high level of pedagogical culture and multilingual culture.

\section{Materials and Methods}

The problem of the use of Kazakh national traditions in the formation of multilingual competence of future teachers has not been investigated yet. Our experiments required using the following methods: solving educational situations, situation of understanding, search situations (creative tasks). Tests, questioning, discussions, observations, expert assessment and etc. were used for quality analysis and assessment of the results of experimental work.

World community appreciates Kazakhstan for its policy of tolerance and international consensus. Kazakhstan achieved this result by encouraging multilingualism, different cultures, freedom of choosing the language for communication and education.

Amanzholova K.B. proposes that successful formation of spiritual and moral components of a person depends on learning folk art, its traditions and modern trends of development in 
today's environment. Kazakh national traditions are democratic and national in nature, content and purpose and so they are valuable in modern society [2].

G.S. Zhusupova and K.B. Amanzholova emphasize that Kazakh traditions have human value and can arouse, develop creative and spiritual tendencies in person. These traditions have been developed for a long period of time and still can be a source for new beginnings $[1,2]$.

All peoples have traditions to celebrate holidays (state holidays, birthday, weddings etc.). There are different definitions of holidays. The variety of definitions proves that these holidays have a long history. As for the Russian culture the word holiday originates from adjective 'idle' which means to be idle, having free time. The Japanese word means 'worship, cult, dancing'. The Kazakh word means 'meeting'. Kazakh people visit relatives and congratulate each other during holidays.

It is necessary to define the concept of 'multilingual person' relating to pedagogical activity. 'Multilingual competence' is considered as a way for successful communication of a future teacher in multilingual educational environment. Another peculiar feature of multilingual competence is deep knowledge of Kazakh national traditions, speech etiquette and communication technologies. Multilingual competence is considered to be a set of acquired professional knowledge, communicative and leader's capacity, skills of selfchecking, empathy, knowledge of verbal and non-verbal communication. This competence is related to interactions with people, skills and knowledge of national traditions $[7,8,9,10$, $11]$.

\section{Results}

The formation of multi lingual competence of future teachers is successful in the process of learning national traditions of different nations in Kazakhstan during professional study in university.

Multilingual competence of future teachers means that they can reach professional selfeducation in the process of special, linguistic, psychological, professional, ethic, didactic, historical and methodological training [12, 13, 14, 15].

An integral part of multilingual competence of future is motivational -valuable, perceptive-affective and ethic components. Motivational-valuable component involves teachers' readiness to work in multilingual environment on a professional level, knowledge of national traditions of Kazakh people, ability to communicate effectively in many languages. Perceptive-affective component embraces the ability to control the results of work and the level of professional development on the basis of knowledge of national traditions of Kazakh people recognizing it a basic multilingual competence. Ethic component means the ability to keep in mind interest of other people and the whole society in multilingual interactions. Respect of ethic norms and means of communication, correct use of knowledge of traditions of Kazakh people in different everyday situations. Operational component involves the ability to choose and organize effective multilingual interactions in educational environment considering topic, aims, space and situation, correctly and accurately express thoughts, listen and perceive information, assess their own speech from ethno cultural spiritual and moral point of view. Socio cultural component involves the ability to consider national and cultural norms of communication, to interact within the framework of different ethnic groups in the dialogue of culture. It helps to learn the values of other culture and community, it is person's spiritual and moral enrichment.

An experiment was conducted with the aim to study how national Kazakh traditions help to form multilingual competence of future teachers in universities. The experiment involved three stages: ascertaining, forming and final. One hundred fifty students learning "Pedagogy 
of Elementary Education" and "Teacher of Physical Education" in the Western Kazakh state university named after M. Utemisov took part in the experiment.

The ascertaining stage included the questionnaire of future teachers. The results' analysis indicated that $51 \%$ of future teachers don't understand the whole problem of multilingual competence. $23 \%$ of future teachers think that a teacher shouldn't be multilingual and described positive and negative sides of this competence. However, $28 \%$ of future teachers don't fully understand that the content and potential of national Kazakh traditions can help to form a multilingual competence and think that these techniques are not fully used in professional training of teachers.

The analysis showed that $49 \%$ of future teachers didn't think themselves to be multilingual competent people. They wrote that they have difficulties connected with selfregulation, self-presentation and the ability to influence representatives of other culture or quickly shift in new multilingual situation. In our opinion the results reflected the situation when problems related to multilingual education of teachers lacked the attention of pedagogical science or were considered in the context of training teachers of foreign languages.

By the end of the experiment the percentage of future teachers having a high level of formed multilingual competence increased from $23 \%$ to $37 \%$, the middle level increased from $29 \%$ to $40 \%$, the low level decreased from $48 \%$ to $23 \%$. The experiment involved three stages- preparatory, basic and integration. All stages provided conditions according to the following principles: subjective experience of students, personal participation, cognitive process, cooperation, individual approach etc.

The preparatory stage included educational situations (discussion of problems emerging in relations among different nations) through joint watching films, video films, discussion books and events reflecting the life in Kazakhstan. Different exercises were used which develop the ability of future teachers to analyze life and professional obstacles and the need to form multilingual competence as a personal quality. A complex of exercises "I and the Situation" was also used. This complex helped to create and maintain the efficiency of future teachers. The exercises provided students with different situations which can emerge in the communication of people with different background.

The second basic stage provided problem- search situations which required the performance of creative tasks. It was the basis for formation multilingual competence. These problem- search situations contributed to personal growth of future teachers, enhancing their knowledge of national Kazakh traditions, positive attitude to the formation of multilingual competence, and strengthened their need in ethno cultural spiritual and moral competence. At the same time these groups of students had stable positive multilingual relations.

The ground of the second basic stage was general cultural training which led to successful results when future teachers began to realize themselves as representatives of an individual culture and consciously understand norms, values and rules of behavior in their own culture. After that it was possible to show and analyze differences between different cultures, and then students were able to notice these differences and use them for effective multilingual interactions. Creative tasks done by participants were devoted to the analysis of national Kazakh traditions, formation of positive inter-ethnic relations and they were considered the most effective method of formation multilingual competence of future teachers in the process of study at the university because it involves informational and operational aspects, it develops the ability to listen to the companion, be sure in communicating with other people, speak in public, build an effective model of multilingual relations with others, prevent and solve conflicts, overcome habits and manners of behavior which can complicate the communication, encourage the formation of openness and readiness to accept the intercultural difference, develop tolerance to representatives of different culture. 
The third integration stage allowed future students using accumulated multilingual experience in learning their own culture and interactions with representatives of different cultures further improve multilingual competence. Future teachers overcoming conflicts learnt to work in multinational environment and be a part of the whole by recognizing multiplicity of truth, enriching their ethno cultural spiritual and moral potential, be opened to new opportunities and attempting to unite with representatives of other cultures.

Thus, the results of experimental control indicated firstly by learning national Kazakh traditions in the process of professional training in higher educational system future teachers form multilingual competence which will help them to adapt in multilingual environment on the basis of knowledge basic norms of behavior, values and beliefs of representatives of different cultures, secondly future teachers enrich themselves ethno culturally, spiritually and morally and better perceive their own national culture, self-identity and traditions.

\section{Discussion}

The use of content opportunities and the potential of national Kazakh traditions enhanced the ways of formation multilingual competence of students. National Kazakh traditions were an important ethno cultural spiritual and moral source for formation multilingual competence of future teachers at the university. The results of the pedagogical experiment proved that the basis for the formation of future teachers' positive multilingual competence is their ethno cultural spiritual and moral enrichment in the process of introducing to the ethnic Kazakh folk traditions during professional training. The results provide grounds to emphasize that the use of problem and search situations in the content of professional training helps future teachers to learn the peculiarities of the folk traditions of the ethnic group of Kazakhstan and gives them an opportunity to comprehend the image of a multinational and multi-religious modern world. The experiment shows that the formation future teacher's multilingual competence involves not the mechanical introduction of question-response knowledge constructs but the consistent deployment of a system of multilingual interactions of the future teacher with the folk traditions of the ethnic group of Kazakhstan. In general, the conclusions assume that the cooperation of the teacher and students in solving multilingual problems is the necessary pedagogical conditions for the formation of multilingual competence of future teachers, the formation of a multilingual orientation of students in educational situations, the accumulation of personal experience of future teachers in the ability to convey the semantic spiritual and moral aspects of the folk traditions of the ethnic group of Kazakhstan in the multicultural educational space of the university, natural integration of multilingual experience into the process of professional and social self-realization.

\section{Conclusion}

Our study couldn't solve all problems in formation multilingual competence. We think the problem of inter disciplinary integration at the university needs further research because it is a way of increasing the efficiency of formation multilingual competence of future teachers in the process of professional training. The results of our study can be used in pedagogical process at universities, during independent work to learn the problems of formation multilingual person and also can be the basis of the process for improving qualification of teachers in educational system. 


\section{References}

1. G.S. Zhusupova, Vestnik of Southern Ural state humanitarian- pedagogical 1, 58 - 69 (2019) DOI 10.25588/CSPU.2019.49.99.004

2. K.B. Amanzholova, Vestnik of Cherepovets state university 5, 42 - 55 (2019) DOI 10.23859/1994-0637-2019-5-92-3

3. U. Ritzau, L.M. Madsen, Applied Linguistics Review 7(3), 305-326 (2016) DOI: 10.1515/applirev-2016-0013

4. C. Perregaux, N. Changkakoti, V. Hutter, M. Gremion, G. Lecomte Andrade, Cahier thématique du PNR 52, 8 - 13 (2016)

5. M.O. Olnova, Multilingualism in Educational Environment 11, 29 - 39 (2019) DOI: https://doi.org/10.35634/2500-0748-2019-11-29-39

6. B.R. Mogilevich, A.A. Kalinkin, Proceedings of the Saratov University. New series. Series. Sociology. Political science 17(2), 136-138 (2017) DOI: 10.18500 / 1818-96012017-17-2-136-138

7. L.A. Shaigerova, R.S. Shilko, Yu.P. Zinchenko, National Psychological Journal 12(1), 3-15 (2019) doi: 10.11621/npj.2019.0101

8. N.A. Astashova, S.K. Bondyreva, O.L. Zhuk, Education and Science 2(2), 27 - 50 (2019) DOI: 10.17853/1994-5639-2019-2-27-50.

9. T.N. Korzh, Problems of Methods of Teaching in university 6(20), 37 - 45 (2017) DOI: 10.18720/HUM/ISSN 2227-8591.20.4.

10. N.P. Nikonova, Baltic Humanitarian Journal 8.3(28), 109 - 112 (2019) DOI: 10.26140/bgz3-2019-0803-0027.

11. Multilingual Environment: Models, Ways of Establishing, Practice: Monograph (Publishing house of Ural university, Yekaterinburg, 2016) DOI 10.15826/B978-57996-1673-1

12. G.S. Drori, M.A. Höllerer, P. Walgenbach, European J. of Cultural and Political Sociology 1(1), 85 - 99 (2014) DOI: 10.1080/23254823.2014.904205

13. L. Portoles, O. Marti, International Journal Of Multilingualism 17(2), 248-264 (2020) DOI: $10.1080 / 14790718.2018 .1515206$.

14. A.A. Vorozhbitova, O.I. Marchenko, A.V. Timofeyev, G.I. Issina, European Journal Of Contemporary Education 7(882-892,)4 (2018) DOI: 10.13187/ejced.2018.4.882

15. E. Zhumabayeva, A.A. Kdyrbaeva, S.A. Nurzhanova, S. Stambekova, E. Uaidullakyzy, Tejuelo-Didactica De La Lengua Y La Literatura 31, 307-323 (2020) DOI: 10.17398/1988-8430.31.307 